\title{
Life scripts help to maintain autobiographical memories of highly positive, but not highly negative, events
}

\author{
DAVID C. RUBIN \\ Duke University, Durham, North Carolina \\ and \\ DORTHE BERNTSEN \\ University of Aarhus, Risskov, Denmark
}

\begin{abstract}
A representativesample of 1,307 respondents between the ages of 20 and 94 was asked how old they were when they felt most afraid, most proud, most jealous, most in love, and most angry. They were also asked when they had experienced their most important event and whether this event was positive or negative. In general, there was a reminiscence "bump" for positive but not negative events. To provide data on life scripts, 87 psychology students answered the same questions for a hypothetical 70-yearold. The undergraduates were more confident in dating positive than in dating negative events, and when they were confident, the distribution of responses predicted the survey data. The results support the idea of culturally shared life scripts for positive but not negative events, which structure retrieval processes and spaced practice.
\end{abstract}

For people over the age of 40, information obtained during adolescence and early adulthood is remembered better than information obtained during the surrounding periods of life (see Rubin, Rahhal, \& Poon, 1998, for a review). This "bump" has been found in studies on wordcued memories (Conway \& Haque, 1999; Hyland \& Ackerman, 1988; Jansari \& Parkin, 1996; Rubin \& Schulkind, 1997a, 1997b; Rubin, Wetzler, \& Nebes, 1986; Schrauf \& Rubin, 1998) by asking for subjects' most vivid memories (Cohen \& Faulkner, 1988; Fitzgerald, 1988), their most important memories (Fitzgerald, 1996; Rubin \& Schulkind, 1997a, 1997b), and their life narratives (Fromholt \& Larsen, 1991, 1992). A bump has also been found in some studies addressing factual information acquired during different periods of life, such as knowledge of historical, political, and cultural events (Belli, Schuman, \& Jackson, 1997; Holmes \& Conway, 1999; Rubin et al., 1998; Schuman \& Rieger, 1992).

Surprisingly, the bump is not found for all classes of emotionally charged memories. Recently, Berntsen and Rubin (2002) asked a sample of 1,241 respondents between the ages of 20 and 93 how old they were during their

\footnotetext{
We thank Jonas Giersing and his colleagues at Gallup Public, Denmark, for their help and Martin Conway, Harvey Marmurek, and Harald Merckelbach for their comments. The study was supported by a grant from the Danish Research Council for the Humanities. NIA Grant AG 16340 helped fund the data analysis and writing of this article. Correspondence should be addressed to D. C. Rubin, Department of Psychological and Brain Science, Duke University, Durham, NC 27708-0086 (e-mail: david.rubin@duke.edu).
}

most important, their happiest, their saddest, and their most traumatic experiences. A clear difference was found for the positive and negative memories: For respondents over 40 , there was a clear bump in the 20 s for the most important and happiest memories; in contrast, the data for the saddest and most traumatic memories could be accounted for by a monotonically decreasing retention function. The distributions for happiest, saddest, and most important memories for respondents in their $60 \mathrm{~s}$ are shown in Figure 1 to illustrate this pattern.

Berntsen and Rubin (2002) argued that standard accounts of the bump as given by Rubin et al. (1998) need to be modified to account for these findings. They argued that three different theoretical frameworks can explain the dissociation between emotionally positive and emotionally negative memories: a cognitive framework, a narrative/identity framework, and an account based on life scripts. The first two frameworks are based on earlier accounts of the bump, modified by clinical and social psychological theory to account for the reduced recall of remote negative memories, whereas the life script account was introduced by Berntsen and Rubin.

All three explanations center on the observation that during the period covered by the bump, substantial life transitions are expected to take place (e.g., Erikson, 1950; Neugarten \& Hagestad, 1976; Rutter, 1989). For people living a prototypical life in a western culture, the period between the ages of 15 and 30 is when people leave home, finish their educations, get a first job, get married, and start a family. According to a cognitive explanation based on the principles of verbal learning 


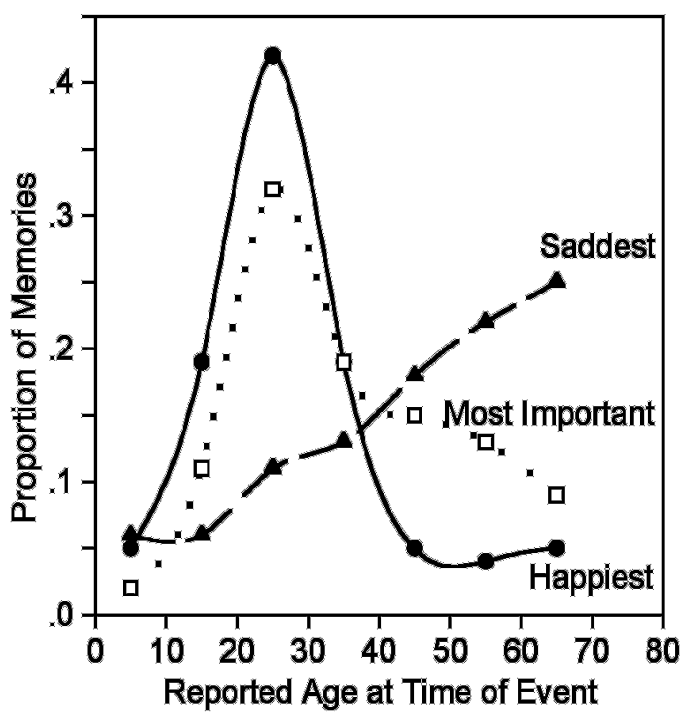

Figure 1. The distribution of the saddest, happiest, and most important memories for participants in their $60 \mathrm{~s}$ from Berntsen and Rubin (in press).

(Rubin et al., 1998), such consequential events followed by relative stability are more distinctive and more rehearsed than are events from earlier and subsequent life periods and thus are better remembered. In a modified version of this framework, the absence of a bump for negative events might be due to a reduced rehearsal of negative events in conversations, owing to social censure (Harber \& Pennebaker, 1992) or to the fact that negative events are followed by more instability than are positive events (Berntsen \& Rubin, 2002; Ruch, Chandler, \& Harder, 1980; Ruch \& Holmes, 1971).

Narrative/identity accounts often take as their starting point Erikson's (1950) theory of psychosocial development, according to which young adulthood is seen as a critical period for the formation of an adult identity. $\mathrm{Cog}$ nitive theorists who follow this view assume that memories from this period have a privileged position in the life narrative because these memories help maintain a stable sense of identity. According to this view, the bump is due to a "preferential retention of events from a period of consolidating of the self" (Conway \& Pleydale-Pearce, 2000, p. 280). The dissociation between positive and negative events shown by Berntsen and Rubin (2002) can be explained as a result of repression, or similar defense mechanisms, working in the service of an enduring ego or self.

The two previous accounts center on mechanisms within the individual. In contrast, in an account based on life scripts, the retrieval of autobiographical memories is governed by culturally shared representations of the prototypical life cycle that locate the majority of important transitional events in young adulthood and favor positive events. Our notion of a life script combines the concept of script as developed by Schank and Abelson (1977) and the idea of the life cycle and culturally sanctioned age norms from research on life-course development (e.g., Foner \& Kertzer, 1979; Neugarten \& Hagestad, 1976; Settersten \& Hagestad, 1996a, 1996b). The notion of life script has many similarities with the concepts of prescriptive time tables (Neugarten \& Hagestad, 1976) and timing norms (Shai, 2002). A script is a series of events that unfolds in a specific order, with each event enabling the events that follow, composing a stereotypical episode, such as eating in a restaurant (Schank, 1982, 1999; Schank \& Abelson, 1977). In the same way, a life script represents a series of events that takes place in a specific order and represents a prototypical life course within a certain culture. In addition to expectations about event sequences, life scripts come with age norms - that is, each transitional event in the life course is assumed to take place within a certain age range. Technological, political, and economic changes, or major historical events, are likely to affect the age-related organization of a society and can either delay or bring forward specific transitional events (Neugarten \& Hagestad, 1976; Shai, 2002). Thus, cohort differences are likely to exist on the content and composition of life scripts.

Though a life script might help to structure individual life narratives, the two concepts are distinct: Life scripts are generic, whereas a life narrative deals with the individual life as actually lived, reconstructed, and narrated by an individual. Life scripts are nonpersonal and apply normatively to all members of the culture, whereas a life narrative is personal. Life scripts represent shared public knowledge, whereas a life narrative refers to private knowledge that is shared with only a few people. Life scripts deal with a fixed temporal order of events, whereas life narratives deal with a lived temporal order. Life scripts are a form of semantic knowledge, whereas life narratives represent episodic/autobiographicalknowledge. Though life scripts might help to structure an individual life story, the two representations can conflict with one another (Luborsky, 1993; Neugarten \& Hagestad, 1976). People know the life script of their society independently of the timing of transitional events in their own lives (Shai, 2002).

Why do we expect life scripts to produce a bump? In a study of life scripts, Settersten and Hagestad (1996a, 1996b) asked 319 American adults in the Chicago metropolitan area to estimate by what age 11 important life transitions should occur. They reported six family transitions (with the mean ages), which were leaving home (22), marrying (27), returning home (28), entering parenthood (29), completing child bearing (41), and entering grandparenthood (52). They reported five educational and work transitions (with the mean ages), which were entry into full-time work (22), exit from full-time schooling (26), settling on career/job (29), reaching the peak of the work trajectory (41), and entering retirement (60). Seven of the 11 transitions were expected to be accomplished between the ages of 20 and 30 . This supports our assumption that some of the findings of the bump 
may reflect retrieval of autobiographicalmemories guided by life scripts.

Why do we expect life scripts to be only about positive events? Although a real life and a truthful life narrative may contain many negative events, a life script does not. A truthful life story will tell about one's struggling, and perhaps one's failing, to overcome obstacles to desirable goals, whereas life scripts deal with transition points that are desirable according to cultural norms. One may be personally unhappy at the day of one's wedding, but the act of marrying is a positive event according to cultural norms. Likewise, postpartum depression exists, but the birth of a child in normative terms is a positive event. As a consequence, negative events do not have a particular time slot in the culturally expected sequence of events. This agrees with the fact that few of the 11 events considered as normative transitions points in Settersten and Hagestad's (1996a, 1996b) studies could be viewed as negative. Similarly, Neugarten and Hagestad (1976) argued that role transitions that occur within the expected time period are unlikely to be experienced as traumatic. Instead, they argue that major stresses can be caused by events that violate the life script (e.g., the loss of a parent in childhood), in that such off-time events can cause problems of adjustment (Shai, 2002). This agrees with Janoff-Bulman's (1988) observation that highly negative events usually contradict our basic assumptions about the world.

How do life scripts influence retrieval of emotional events? Life scripts provide search descriptions for times when one is most likely to have experienced the emotion. So for "happy" or "in love," there is a time period during which one is most likely to have such emotions, according to shared cultural norms. Even though sadness and anger may be as expected and as common as being happy and in love over the overall life time, there is no particular time period to search for these emotions. If no specific time slot in a life script is allocated to certain types of events, they will not benefit from a life script that supports and structures their retrieval and, thus, by default, should show the monotonically decreasing retention function of normal forgetting consistent with Berntsen and Rubin's (2002) findings for saddest and most traumatic memories.

The present work extends Berntsen and Rubin (2002) in an attempt to test the life script explanation. In contrast to the cognitive and the narrative/identity explanations, the life script account has the potential to make highly specific testable predictions because it is possible to measure life script knowledge. We have been unable to find any empirical studies that have examined people's life scripts for differently charged emotional events. Therefore, our Study 2 examines the life script for the classes of events that Berntsen and Rubin used, in addition to the classes of events that we are using in our Study 1 . If the views presented here are correct, requests for positive, but not negative, events should form a bump; our participants will be much more confident and in better agreement about the dating of positive versus negative events; and when they are confident, they will be better at predicting the recall data.

\section{STUDY 1}

In Study 1, we asked a large stratified sample ranging in age from 20 to 94 years how old they were when they had felt most afraid, most proud, most jealous, most in love, and most angry. In addition, we asked how old they were when they experienced their most important event and whether this event was positive, negative, or mixed. We do not address the frequency of positive versus negative memories or the differences in their intensity (Matlin \& Stang, 1978). Also, we do not separate retention of the emotion from the retention of the rest of the event. Thus, it is not possible here to decide whether the intensities of the different emotions fade at the same rate (Walker, Rodney, \& Thompson, 1997). Emotions might vary with respect to a number of dimensions other than valence. In the present context, the most important dimensions to consider are whether the emotions are basic or complex (e.g., Ekman, 1992; Panksepp, 1992), whether the emotions are associated with higher or lower levels of arousal (e.g., Smith \& Ellsworth, 1985), whether their duration is typically long or short (e.g., Poulsen, 1991), and whether they address the person's self (Lewis, Sullivan, Stanger, $\&$ Weiss, 1989). To ensure that none of these dimensions seriously confounded our data on valence, the selection of positive and negative events that we used covers emotions that vary on these dimensions.

\section{Method}

Participants. A representative sample of the Danish population above the age of 16 participated. The respondents were selected from all geographic areas of Denmark, except Greenland and the Faroe Islands, as part of an omnibus survey by Gallup Public, Denmark. All respondents were able to speak and understand Danish. In each household, 1 or 2 respondents were randomly selected via a combined criterion based on number of household members above the age of 16 and their birthdays. The response rate for the entire omnibus was $56 \%$. To exclude minors and to provide conventional decade boundaries, only respondents above the age of 19 were included in the present study. Table 1 shows the number of male and female respondents sorted by decade of life and by the number of participants in each age group who answered each question by giving a date or by explicitly stating that they had no memory of that type. No dates were provided in response to any of the five questions requesting a date by 71 of our 1,307 respondents.

Procedure. The data were collected by 120 interviewers via face-to-face interviews in the respondents' homes. The questions of relevance for the present study were preceded only by demographic questions in the omnibus. The interviews were conducted in Danish. An English version of the set of questions for the present study is presented in Appendix A. Half of the respondents were asked the questions in the same order as in Appendix A. For the other half, the order of questions was reversed, except that Questions 6 and 6 a were presented last in both versions. Response options for Questions 1-6 were as follows: (1) "I was around [age in event] years old," (2) "I have no memories in which I feel very afraid/proud/jealous/ much in love/angry/no memories of epoch-making events," and (3) "I don't want to answer." Response options for Question 6a were 
Table 1

Description of Participant Population and Number of Participants With Dated Memories and With No Memory

\begin{tabular}{|c|c|c|c|c|c|c|c|c|c|c|c|c|c|c|c|}
\hline \multirow[b]{3}{*}{ Age Range } & \multirow[b]{3}{*}{$n$} & \multirow[b]{3}{*}{ Women } & \multirow[b]{3}{*}{ Age } & \multicolumn{12}{|c|}{ Participants Responding Explicitly With Date or No Memory of That Type } \\
\hline & & & & \multicolumn{2}{|c|}{ Fear } & \multicolumn{2}{|c|}{ Pride } & \multicolumn{2}{|c|}{ Jealousy } & \multicolumn{2}{|c|}{ Love } & \multicolumn{2}{|c|}{ Anger } & \multicolumn{2}{|c|}{ Importance } \\
\hline & & & & Date & None & Date & None & Date & None & Date & None & Date & None & Date & None \\
\hline $20-29$ & 234 & 109 & 24.84 & 151 & 80 & 192 & 39 & 119 & 109 & 210 & 15 & 160 & 69 & 178 & 52 \\
\hline $30-39$ & 270 & 143 & 34.56 & 192 & 75 & 223 & 41 & 147 & 118 & 253 & 12 & 175 & 91 & 218 & 49 \\
\hline $40-49$ & 255 & 146 & 44.00 & 172 & 73 & 192 & 55 & 123 & 121 & 222 & 23 & 153 & 87 & 201 & 43 \\
\hline $50-59$ & 204 & 109 & 54.43 & 138 & 59 & 137 & 56 & 177 & 116 & 177 & 20 & 116 & 76 & 147 & 48 \\
\hline $60-69$ & 158 & 85 & 64.32 & 92 & 57 & 91 & 59 & 40 & 112 & 123 & 26 & 70 & 79 & 103 & 48 \\
\hline $70-99$ & 186 & 128 & 78.03 & 87 & 87 & 92 & 80 & 33 & 137 & 134 & 31 & 60 & 108 & 99 & 74 \\
\hline Total & 1,307 & 720 & 46.33 & 832 & 431 & 927 & 330 & 539 & 713 & 1,119 & 127 & 734 & 510 & 946 & 314 \\
\hline
\end{tabular}

(1) “positive," (2) “negative," (3) “mixed," and (4) "I don’t want to answer."

The interviewer recorded responses on a laptop computer. To ensure understanding, each question and the response options for each question were printed on a demonstration card that was shown to the respondent while the question was being asked. If the respondent preferred, he or she could read the questions and response options directly from the computer screen. If the respondent found one or more questions too intimate, he or she was offered the opportunity of typing his or her responses directly into the computer while the screen of the computer was turned away from the interviewer.

The questions for Study 1 were introduced by a brief explanation clarifying that the questions were about memories from the respondent's personal life. It was stressed that the respondent did not have to answer the questions if he or she found them to be too private. It was also stressed that the purpose of the study was scientific and that no political or financial interest was involved.

\section{Results}

Reports of no memories. Table 2 shows the rank order of the proportion of respondents who reported no memories in response to each of the emotion questions and to each of the other questions. For the sake of comparison, this table also includes the proportions of no reports from Berntsen and Rubin (2002).

The most striking finding was that more than half of the respondents $(55 \%)$ stated that they had no memories of being very jealous. By comparison, only $10 \%$ stated that they had no memories of being much in love, and $41 \%$ stated that they had no traumatic memories. Rather than reflecting the actual frequencies of experiences of jealousy in our respondents' lives, the high number of no reports is likely a reflection of a bias in reporting or memory. The same is most likely true for the high number of no reports on anger and fear. Both emotions are classified as basic emotions with innate neural substrates, innate facial expressions, and distinct feeling states (e.g., Ekman, 1992; Panksepp, 1992). Thus, the likelihood that intense fear and anger were never experienced by $30 \%-40 \%$ of a representative sample of Danes seems very small. It should be noted that a response option worded as "I don't want to answer" was offered for all questions. This option was used with the same frequency across the questions-namely, by around 50 of the 1,307 respondents (4\%). Thus, when a participant chose to answer that he or she had no memory of the par- ticular event in question, we should expect this answer to reflect a genuine experience of being unable to easily retrieve a memory for an event in which they were extremely jealous, angry, or afraid, and not an unwillingness to answer; the bias appears to be in memory rather than in reporting. Therefore, some mechanism, such as a life script, is needed to explain a decreased accessibility of memories associated with jealousy, anger, and fear as compared with memories associated with other emotions.

The distribution of emotionally charged memories. Figures 2-4 present the basic results of Study 1. Each panel shows the separate results for participants in their 20s, 30s, 40s, 50s, 60s, and those in their 70s and above. To present all groups in one panel for each question, each younger group was offset by 0.2 so that the curves would not overlap: Thus, the participants in their $60 \mathrm{~s} \mathrm{had}$ 0.2 added to their scores; the participants in their $50 \mathrm{~s}$, 0.4 ; the participants in their $40 \mathrm{~s}, 0.6$; the participants in their 30s, 0.8; and the participants in their 20s, 1.0. Because this causes the $y$-axis to go from 0 to 1.8 instead of from 0 to 0.6 , the figure compresses the visual differences by a factor of three. For all figures, the proportion of memories occurring in the most recent decade was corrected for the fact that the participants in that decade had on the average lived through only about half of the decade. In order to do this, the mean number of years

Table 2

Cues Rank Ordered by Proportion of Respondents Reporting No Memory of That Type

\begin{tabular}{lrl}
\hline \multicolumn{1}{c}{ Cue } & $p$ & $S E$ \\
\hline & Emotion Cues & \\
Most jealous & .55 & .014 \\
Most angry & .39 & .013 \\
Most fear & .33 & .013 \\
Most pride & .25 & .012 \\
Saddest & $\mathbf{. 1 3}$ & .009 \\
Most in love & .10 & .008 \\
Happiest & $\mathbf{. 1 0}$ & \\
& & $\mathbf{. 0 0 9}$ \\
Most traumatic & Other Cues & $\mathbf{. 0 1 4}$ \\
Involuntary & $\mathbf{. 4 1}$ & .012 \\
Most important & $\mathbf{. 3 8}$ & $\mathbf{. 0 1 2}$ \\
Most important & .24 & $\mathbf{. 2 4}$ \\
\hline
\end{tabular}

Note-Values from Berntsen and Rubin (2002) are in bold. 
lived past the decade boundary was calculated as the mean age of the participants in that group plus 6 months (because the participants who reported their ages as $n$ years old on the average actually had lived $n$ and a half years) minus the decade boundary. This number was divided into 10 (the number of years in the decade) and was multiplied by the number of memories observed in that decade before the proportions shown in the figures were calculated. For instance, the average age of the participants in their 40 s was 44.00 years. They produced 26 memories of pride in their $40 \mathrm{~s}$. We multiplied $26 \times$ $10 /(4.00+0.50)$ in order to infer that there would have been 58 memories in the decade if all the participants had been tested the day before their 50th birthday.

Figures 2-4 present the probability of a memory's being reported in each decade of life along with a standard error bar calculated by $\sqrt{ }[p(1-p) / n]$. Given the large number of participants, the standard errors are small (.05 or less in all cases for anger, fear, love, and pride, and .08 or less in all cases for importance, positive/ negative, and jealousy) and, therefore, at times are hidden behind the dots indicating the means. The results are robust. Within each figure, the differences we mention are usually greater than two standard errors, and, more importantly, unless specifically noted, they vary in incremental, systematic ways for the six age groups shown in each figure. The possibility of such patterns occurring by chance is exceedingly small.

Of the most important memories (Question 6 in Appendix A), 481 were rated as positive, 266 as negative, and 197 as mixed. Thus, roughly half of the most important memories were rated as positive. This proportion held for each age group with 49\%, 53\%, 49\%, 53\%, $49 \%$, and $52 \%$ of the participants between the ages of 20 and 70 rating their most important memories as positive, respectively. In the top panel of Figure 2 are shown the data for the participants' memories of their most positive important event. There was a peak in the 20s for all participants, which was more pronounced in the older participants. A radically different pattern is seen in the bottom panel, which presents the distributions of respondents' most important memories when the emotional content was classified as negative or mixed. No bump was detected for any of the age groups. For all age groups, a slow increase in the number of memories was found from the most remote to the most recent decades of life, though the curves are somewhat noisy. The data pattern resembles the data for respondents' saddest and most traumatic memories reported by Berntsen and Rubin (2002) and adds support to their main finding that a bump was present only for emotionally positive memories. Moreover, since the respondents in the present study were asked to rate the emotional content after they had retrieved and dated the memory, a deliberate search for positive versus negative memories could not have led to the differences between the positive and negative important memories.

Figure 3 presents the data for people's memory of the two positive emotions, and both are similar to the posi-
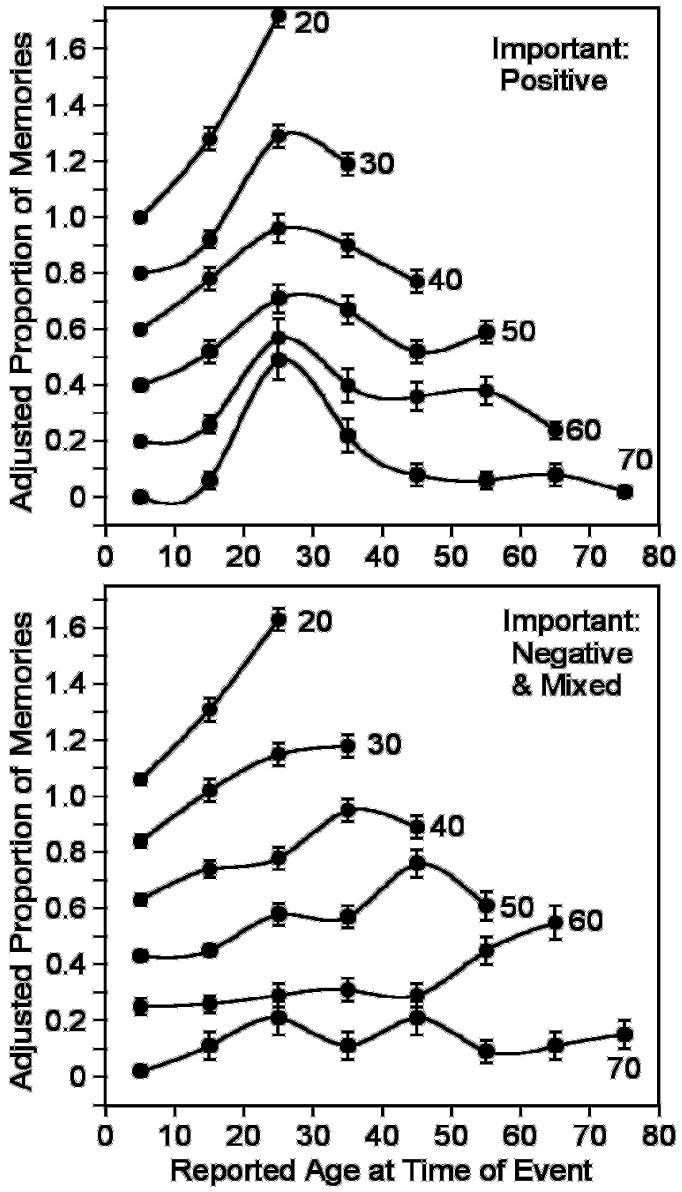

Figure 2. The distribution of the most important autobiographical memories. The top panel shows important memories that were rated as positive; the bottom panel, those rated as negative or mixed. Each decade age group is labeled by the youngest age included and is offset by 0.20 from the next oldest age group to make all plots visible. Standard errors are shown for all plots.

tive important events shown in Figure 2. However, the bump for most in love was located earlier than the bump for memories of most important positive and most proud memories and the bump for happiest memories reported by Berntsen and Rubin (2002). Even though positive valence plays a crucial role for the presence of a bump, the specific emotional content is able to affect its temporal location.

Figure 4 presents the data for memories of the three negative emotions. The top panel shows the ages during which respondents felt most jealous. Although consistent evidence was found for a bump, its location varied. In the middle panel, which shows the ages during which respondents felt most angry, a clear increase can be seen in responses regarding the most recent decades of life. In addition, there is an indication of a bump in the teens for respondents above the age of 40 . However, the size of this bump is small and, except for that for respondents in their 70s, it is lower than the increase of memories from 

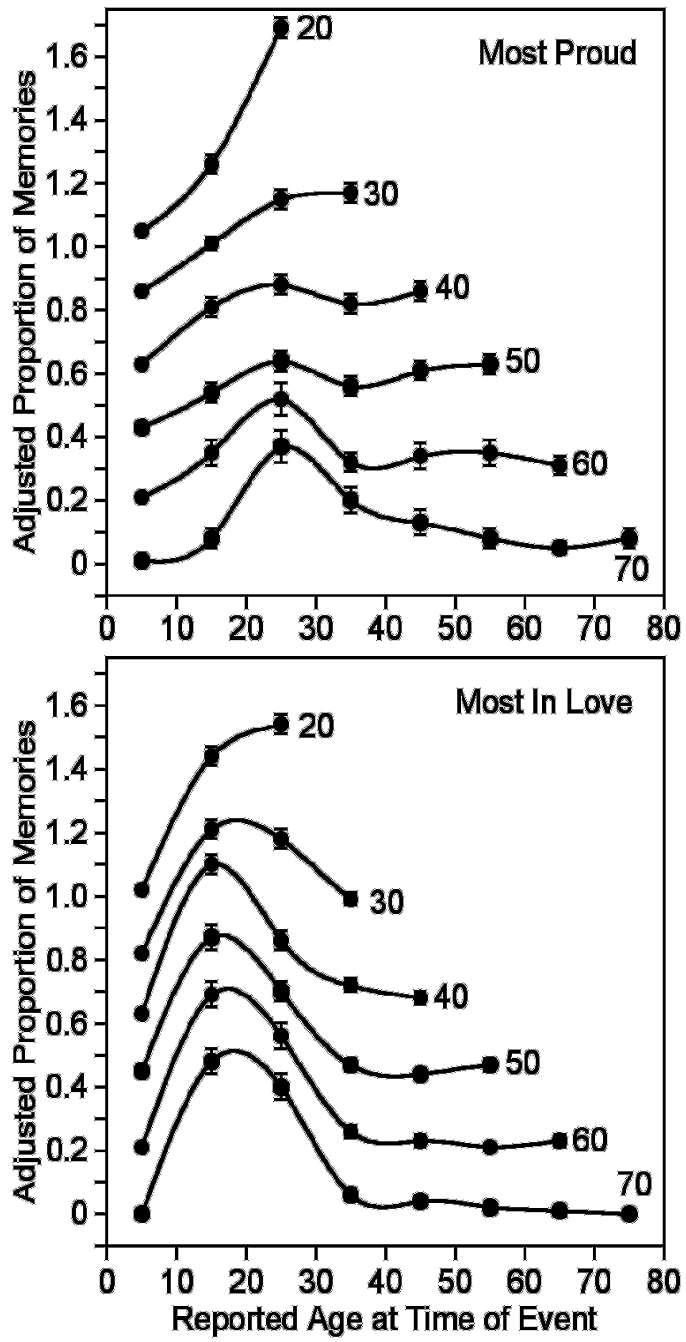

Figure 3. The distribution of autobiographical memories for positive emotions. The top panel is for events in which participants were most proud; the bottom panel is for events in which they were most in love. Each decade age group is labeled by the youngest age included and is offset by 0.20 from the next oldest age group to make all plots visible. Standard errors are shown for all plots.

the most recent decades. In the bottom panel, which shows most afraid memories, all distributions are relatively flat, although an increase in memories from the most recent 1-2 decades is seen in most cases. Only respondents in their 70s showed a bump in their 20s. Thus, the data for memories of feeling most angry and most afraid followed the same pattern as the data reported by Berntsen and Rubin (2002) on respondents' saddest and most traumatic memories. A clear bump was not found in any of these datasets, the distributions were relatively flat, and there was an increase in memories from the most recent decades of life.

To summarize, the distributions of memories for important events rated positive-for being most in love and for being most proud-were similar in that they all showed a clear bump between the ages of 10 and 30 , but the location of this bump occurred in the teens for memories of being most in love and in the 20s for the other two classes of positive memories. The distributions of memories for important events rated negative-being most angry and most afraid - were similar to one another but differed from the distributions of the positive events, showing, at most, a small bump between the ages of 10 and 30 , and either curves that were relatively flat or curves that could be described as monotonically decreasing retention functions. The distribution of memories of being most jealous had a bump, but it occurred in different decades.

War and peace. An examination of the figures presented here and in our earlier study (Berntsen \& Rubin, 2002) reveals that the 70-year-old respondents often showed a bump for negative events and might have a larger bump for all events as compared with the younger groups. There are two classes of explanation for this apparent effect. The first, based on the age of the respondents, is that although the bump exists in a host of conditions for people as young as 40, it increases later in life, perhaps as a part of life review (Butler, 1964; Fitzgerald, 1996). The second explanation is based on historical time. Denmark was occupied by Germany from April 1940 to May 1945. At the time of the survey in 2001, respondents in the 50-year-old group or younger had not yet been born during the occupation, those in the 60-year-old group would have been between 0 and 13 years old, and those in the 70-year-old group, which included respondents from 70 to 94 , would have been between 9 and 38 years old. Thus, the events experienced during the occupation could be what is causing the bump for negative events for the 70-year-old respondents and an increase in the first decade of life for fear for the 60year-old respondents. To compare these two explanations, we did two types of analysis: The first, which was used to investigate the possibility of increased reminiscence with age, was based on the age of the respondents; the second, which was used to investigate historical influences, was based on the reported calendar date of the memory. Both analyses are shown in Table 3.

If the bump is larger in the 70-year-old respondents, the probability of a memory of an event's occurring in their 20s should be greater. We calculated this for Study 1 and for the data from Berntsen and Rubin (2002). As can be seen in Table 3, the effect was in the right direction for all cues except the request for the involuntary memories. However, when individual questions were considered, only questions regarding most trauma and most fear, emotions that one might associate most with a foreign invasion, reached significance.

For the historical analysis, all memories were converted from the reported-age-of-the-respondent-at-thetime-of-the-event measure, used throughout the rest of this article, to calendar year. We used three 4-year periods: before (1936-1939), during (1941-1944), and after (1946-1949) the occupation, removing the transition 

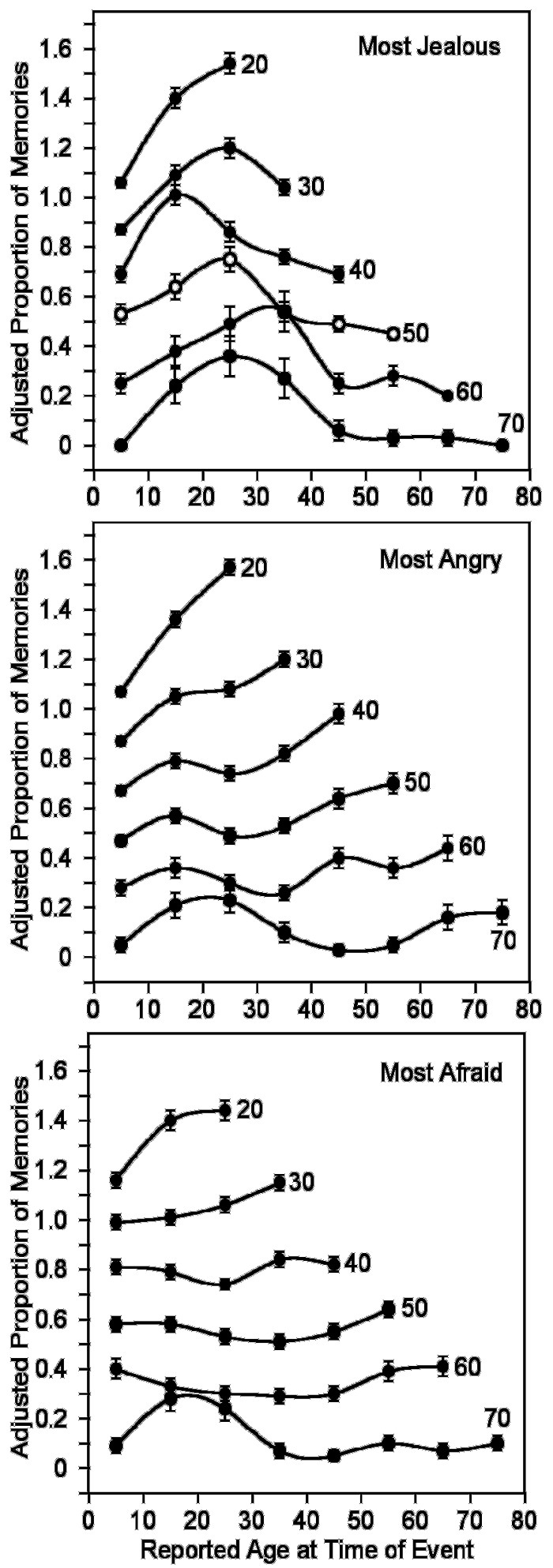

Figure 4. The distribution of autobiographical memories for negative emotions. The top, middle, and bottom panels are for events in which participants were most jealous, most angry, and most afraid, respectively. Each decade age group is labeled by the youngest age included and is offset by 0.20 from the next oldest age group to make all plots visible. Standard errors are shown for all plots. years of 1940 and 1945 from the initial analysis because these included both occupation and no occupation. In the data reported in Study 1, there were 261 respondents born by 1936 and 511 born by 1949 . (For Berntsen \& Rubin, 2002, these values were 273 and 518, respectively.) Thus, there were about twice as many individuals who could have had a memory for the later than for the earlier years being considered.

Because we did not want to reduce the range of ages of the respondents during the war years for an analysis intended to contrast age and historical time, we did not want to include only the 261 respondents who were alive for the whole period. We therefore normalized the frequencies of memories for each year as if there were 500 respondents alive in each year. We did this by multiplying the observed number or memories in a given year by 500 and dividing by the number of respondents who were born by then. For example, there were eight fear memories recorded for 1942 and 363 respondents had been born by 1942 . We therefore recorded $8(500 / 363)$, or 11.02 fear memories for 1942 instead of the raw value of 8 . The total number of normalized memories for each cue for the three periods is presented in Table 3. For fear and trauma memories, the two cues that had significant differences in the analysis based on the age of the respondents, there were twice as many memories for the time period during the occupation as for the surrounding periods. We plot these data, using two-year intervals and including 1940 and 1945, in Figure 5. Frequencies for two other memories changed in a clear fashion with the beginning and end of the occupation of Denmark: the saddest and happiest memories. Saddest memories followed the pattern of fear and trauma memories, but less dramatically. Happiest memories increased for the time period after the occupation. In the years from 1936 to 1944, there were always between 0 and 5 happy memories reported in the raw data. In 1945 and 1946, the raw frequencies jumped to 14 and 13 , respectively.

We cannot rule out the hypothesis that reminiscence increases with age, but the two questions that show significant difference with the age of the respondents also show clear and very large effects of the occupation of Denmark. The occupation of Denmark provides ties from individual history to cultural history and may reflect the operation of a life script developed specifically for the "war generation." When asked for their most traumatic and fearful memories, this group used the war period as a search description, because this period of their life is culturally agreed on as having been traumatic.

\section{Discussion}

The main results were consistent with Berntsen and Rubin's (2002) findings: Memories associated with positive emotions showed a bump for young adulthood, whereas with the exception of jealousy, memories associated with negative emotions did not, or did so to a much smaller degree. Thus, the present study replicates the reduced recall of remote negative events. Moreover, the 
Table 3

Memories Before, During, and After the Occupation of Denmark

\begin{tabular}{|c|c|c|c|c|c|c|}
\hline \multirow[b]{2}{*}{ Emotion } & \multicolumn{3}{|c|}{ Proportion in $20 \mathrm{~s}$} & \multicolumn{3}{|c|}{ WW II Occupation } \\
\hline & Age 70 & Age 60 & $\chi^{2}$ & $\overline{\text { Before }}$ & During & $\overline{\text { After }}$ \\
\hline \multicolumn{7}{|c|}{ Berntsen and Rubin (2002) } \\
\hline Happiest & .55 & .45 & 1.72 & 19 & 23 & 38 \\
\hline Saddest & .19 & .12 & 1.55 & 10 & 22 & 13 \\
\hline Most important & .37 & .33 & 0.10 & 5 & 17 & 14 \\
\hline Most traumatic & .18 & .06 & $4.25^{*}$ & 5 & 22 & 9 \\
\hline Involuntary & .10 & .15 & 0.19 & 17 & 14 & 14 \\
\hline \multicolumn{7}{|c|}{ Experiment 2} \\
\hline Most fear & .24 & .11 & $4.63^{*}$ & 19 & 43 & 18 \\
\hline Most pride & .38 & .33 & 0.21 & 5 & 9 & 8 \\
\hline Most jealous & .36 & .29 & 0.17 & 0 & 8 & 7 \\
\hline Most in love & .40 & .37 & 0.16 & 25 & 40 & 42 \\
\hline Most angry & .23 & .11 & 2.47 & 7 & 12 & 9 \\
\hline Most important & .36 & .24 & 2.62 & 7 & 12 & 18 \\
\hline
\end{tabular}

Note-The frequencies for the last three columns were normalized by assuming that there were 500 respondents alive during the years 19361949. $* p<.05$

three classes of memories associated with the highest number of no reports all dealt with negative emotions (jealousy, anger, and fear), which further supports that the access to emotionally unpleasant memories is reduced.

However, the results also show that even though positive valence plays a crucial role for the presence of a bump, the specific emotional content is able to affect its temporal location. Memories of being most in love came mostly from the period between the ages of 10 and 20 , whereas memories for other highly positive events formed a bump with a peak between the ages of 20 and 30. Also, not all memories of highly negative events showed a monotonically decreasing retention function as the one reported by Berntsen and Rubin (2002) for memories of the most traumatic and the saddest events. In the present study, such a pattern was found for memories of most important events rated as neutral or negative and for memories of being most angry and most afraid, whereas memories of being most jealous showed a different pattern.

The present findings are consistent with the assumption that the retrieval of emotionally charged events is formed by respondents' life scripts: Many negative events would not be part of the respondents' life scripts and therefore show a monotonically decreasing retention function, consistent with the findings. The fact that memories for feeling most in love derived from the respondents' teen years, whereas memories for other highly positive events peaked in the 20 s, seems to be in perfect agreement with normative expectations of the course of life in a modern western society. The finding that memories for being most jealous had a peak between the ages of 10 and 30 for five out of six age groups could indicate a search based on knowledge of the temporal slot for love combined with variable estimations of when in life the stormy heights of romantic love are most likely to cause conflict and jealousy. The high number of no reports of memories of being most jealous, most angry, and most afraid might reflect that such events are not included in most Danes' life scripts, so that no life script is available to help the retrieval of such events. Obviously, these interpretations are post hoc and speculative. Because we have been unable to locate any empirical studies that have investigated people's life scripts for differently charged emotional events, we conducted Study 2 in order to provide such data.

\section{STUDY 2}

The purpose of this study was to obtain data on life scripts that could guide retrieval. There are at least two ways of conceptualizing the process of retrieval and narration of the personal past. One is based on cognitive and emotional structures of a particular person's life, which can be conceptualized as life time periods and general events (Conway \& Pleydell-Pearce, 2000), landmark events (Shum, 1998), or turning points (Clausen, 1995). Such structures have in common that their actual content is particular to the individual since it derives from his or her life. Another type of retrieval process is based on shared ideas within a given culture of what is expected for people in general, such as the types of events that are expected to happen at certain times in people's lives-for example, graduation, first employment, marriage, and childbirth (e.g., Bluck \& Habermas, 2000; Neugarten \& Hagestad, 1976; Settersten \& Hagestad, 1996a, 1996b). A life script is a schema of such culturally expected events. How should one go about collecting empirical data on such shared knowledge structures? A standard way to obtain a schema independent of the recall of actual instances is to have people generate imaginary instances (Rubin \& Kontis, 1983; Rubin, Stolzfus, \& Wall, 1991; Rubin, Wallace, \& Houston, 1993) - that is, to simulate the behavior of imagined older adults (Baltes \& Goulet, 1971). We do

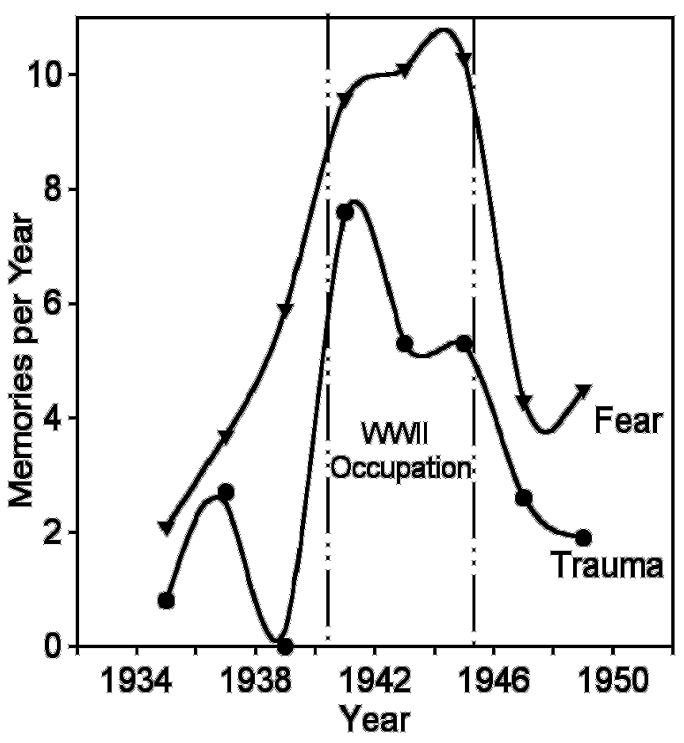

Figure 5. The distribution of autobiographical memories for most traumatic and most fearsome memories plotted by calendar year. 
so here in what we believe to be the first empirical study of people's life scripts for emotional events.

\section{Method}

Participants. To construct a life script, the participants had to be able to understand the task and have an idea of cultural norms if they existed, but not be old enough to make the judgments with respect to their own lives. We therefore chose 87 undergraduate psychology majors at the University of Aarhus (68 females, 19 males; mean age, 26.2 years, range 21-41).

Procedure. The participants were informed that the purpose of the study was to obtain information about cultural norms and expectations regarding the distribution of emotional events across the life span. They were asked to imagine an average 70-year-old male or female and to estimate this person's age during each of a series of emotionally charged events. The instructions were read aloud by the experimenter and printed on the first page of the questionnaire. Translated into English they are as follows:

This study deals with cultural norms and expectations about the distribution of emotional events across the life span. Imagine an average 70 year old, who is looking back at his or her life, thinking about a range of different events. Your task is to give an estimate of this person's age at the time when each of these events took place. For each question, please write what you think is the most likely age in years (do not use ranges) and afterward rate on the scale how confident you are that your estimate is in the right decade of life (i.e., how confident you are that it is correct \pm 5 years). If you have no idea as to when an event is most likely to have occurred, use your best guess and fill in each blank. There are no correct or incorrect answers. We are interested in your intuition about when each of these events is most likely to occur for a typical person.

English versions of the questions are presented in Appendix B. For each question, the participants filled in the estimated age. Afterward, they rated how confident they were that their estimate was in the right decade of the imagined person's life. The scale had seven points $(1=$ I have absolutely no confidence $; 7=$ I am totally confident). Half of the participants were asked the questions in the same order as those in Appendix B. For the other half, the order of questions was reversed. The phrases used in these questions matched the questions in Study 1 and those in Berntsen and Rubin (in press). The participants were instructed not to think of a particular person whose life they knew.

\section{Results and Discussion}

Table 4 presents the results for the questions, rank ordered by mean confidence in the estimated dates, indi- cating the extent to which the events were dated as part of a life script. Confidence ratings for the estimated ages were higher for the important and positive events compared with those for the negative events; the mean confidence ratings for the three positive events versus the five negative events were 4.38 versus $3.52[t(86)=7.70$, $p<.0001]$. In addition, there was a significant negative correlation between the mean confidence ratings and the standard deviations of the estimated ages, as evidenced by a Spearman rank-order correlation $(R=-.72, p<$ $.05)$; the more confidence there was in the age estimates, the closer the estimates were to their mean. This supports the claim that the confidence ratings can measure the extent to which the dated events are allocated a specific slot in a life script; when individual participants were more confident of their estimated dates, the dates were more similar across participants. The difference between the confidence ratings of the dating of positive and negative events therefore supports our prediction that highly positive events are an integrated part of the participants' life script to a much larger extent than are highly negative events.

Table 4 also shows the number of the events distributed across the 7 decades of life. The top three events on the confidence scale peaked in the 20 s, with $51 \%$ of the events located in this decade. The pattern was less clear for feeling most proud and for the five negative events. To compare these distributions with the actual memory distributions found in Study 1 and those in Berntsen and Rubin (2002), Figure 6 shows the distribution of each event type together with the relevant memory distribution from the previous survey studies for the respondents in their 60s. This age group was selected because the participants in the present study were instructed to imagine the life course of a person at the end of this decade. The life script distributions are presented with dotted lines. The purpose of each comparison was to see to what extent the memory data in the survey studies were predicted by the life script data obtained in the present study and whether the accuracy of predictions varied as a function of the confidence ratings. The figures are presented in the same order as the rank order of the confidence ratings in Table 4.

Table 4

The Life Script as Indicated by the Number of Participants Who Dated an Event in Each Decade

\begin{tabular}{lccrrrrrrr}
\hline & & \multicolumn{7}{c}{ Decade of Life } \\
\cline { 4 - 9 } \multicolumn{1}{c}{ Question } & Confidence Rating & $S D$ in Age & Os & $10 \mathrm{~s}$ & $20 \mathrm{~s}$ & $30 \mathrm{~s}$ & $40 \mathrm{~s}$ & $50 \mathrm{~s}$ & $60 \mathrm{~s}$ \\
\hline Most in love & 4.77 & 4.62 & 0 & 37 & 47 & 2 & 1 & 0 & 0 \\
Most important & 4.59 & 8.61 & 0 & 7 & 47 & 26 & 4 & 0 & 3 \\
Happiest & 4.26 & 11.21 & 1 & 4 & 40 & 31 & 2 & 2 & 7 \\
Proudest & 4.13 & 12.26 & 1 & 12 & 24 & 27 & 12 & 9 & 2 \\
Saddest & 4.06 & 16.02 & 0 & 5 & 5 & 7 & 17 & 19 & 34 \\
Most jealous & 3.85 & 10.33 & 3 & 27 & 37 & 7 & 11 & 1 & 1 \\
Most fear & 3.72 & 20.67 & 28 & 18 & 9 & 10 & 5 & 7 & 10 \\
Most trauma & 3.07 & 14.47 & 5 & 17 & 21 & 20 & 14 & 6 & 4 \\
Most anger & 2.97 & 14.18 & 2 & 18 & 7 & 28 & 18 & 8 & 6 \\
\hline
\end{tabular}

Note-Questions ordered by confidence ratings. 

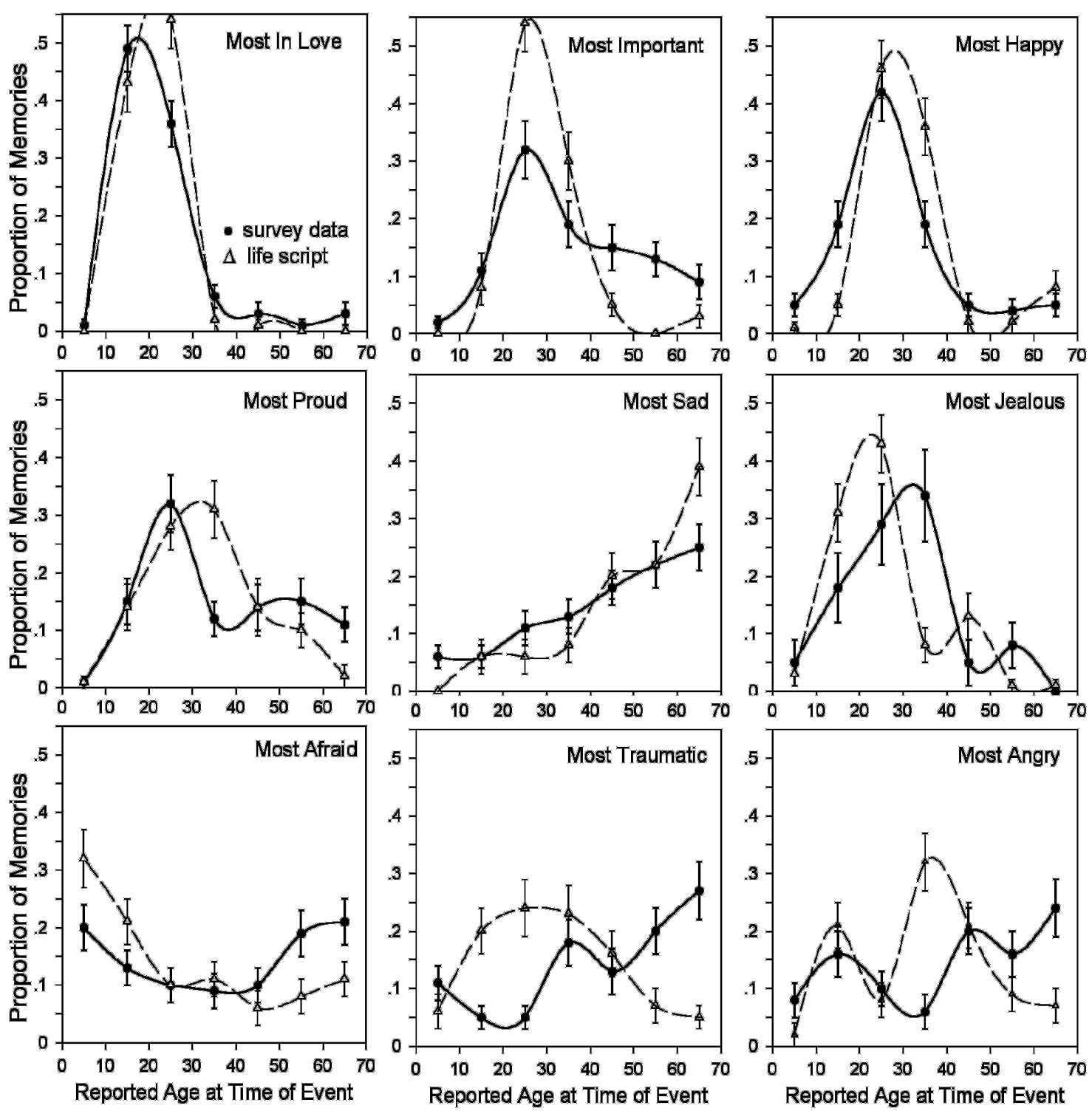

Figure 6. A comparison of the distributions of autobiographical memories from survey participants in their 60s with the distribution of autobiographical memories of a hypothetical 70 -year-old person, according to the estimates of undergraduates. The emotions are shown in the same decreasing confidence order as that in Table 4. Standard errors are shown for all plots.

The life script data obtained in the present study to a large extent matches the distributions of the survey data for the most important memories and for memories of being most in love, happiest, proudest, and saddest. These events also obtained the highest confidence ratings on the estimated dates for their occurrence. The life script data were more poorly matched to the distributions of memories of being most jealous and most afraid, and the data formed a poor match for the respondents' most traumatic memories and their memories of being most angry. The latter two events had the lowest confidence ratings on the estimated dates. In short, the ability of life script data to predict the distributions of memories across the life span varied as a function of the participants' confidence ratings of the estimated dates.
In addition, the life script data put the estimates for being most in love, happiest, and proudest later than in the survey studies. The peak for most in love in the second decade of life was present also in the memory distribution for the same age group (respondents in their 20 s) in Study 1. The peak of proudest and happiest events in the thirties could reflect an idea among the undergraduates in Study 2 that the best experiences are still to come-an expectancy that sadly is not confirmed by the respondents in the survey.

The distribution of the age estimates for saddest events showed a slow increase over life span with fewer sad events being in the first decade of life and most being in the most recent decade. These estimates suggest that the frequency of highly sad events increases over the life 
span. If so, the monotonically decreasing curve found in Berntsen and Rubin (2002) for respondents' saddest memories is not a retention function but simply a reflection of the way life is-it gets sadder and sadder with age. This view is similar to earlier but now rejected theories on the development of affect across life. Recent studies show that negative affect is reported and observed less often in older adults than in younger adults (see Charles, Reynolds, \& Gatz, 2001; de Vries, Blando, Southhard, \& Bubeck, 2001; Mroczek, 2001, for reviews). Since the distribution matches the distribution of memories for saddest events in the survey, this could be taken to indicate the operations of an underlying life script in both cases. However, this interpretation is contradicted by the relatively low confidence ratings and high standard deviations for the undergraduates' estimates of saddest events (cf. Table 5).

\section{GENERAL DISCUSSION}

The findings show the existence of scripts for the expected temporal locations of highly important and highly positive events, but not of highly negative events: In Study 2, the estimated dates of when an average 70-yearold had felt happiest, most in love, and most proud were associated with significantly higher confidence ratings than were the estimated dates of when the same imagined average person had felt saddest, most jealous, most afraid, most angry, and experienced his or her most traumatic event. Moreover, the mean ratings of confidence correlated negatively with the standard deviations, which shows that the individual confidence ratings increased with increasing agreement across participants as to the temporal location of the imagined events. This suggests that a common, underlying, culturally shared conception (i.e., a life script) was reflected in the individual confidence ratings. The life script data obtained in Study 2 followed the distributions of the memory data obtained in Study 1 and those in Berntsen and Rubin (2002) for important and highly positive events, whereas the same data to a much less extent explained the distributions for emotionally negative events and were very poor for those negative events for which confidence ratings on the estimated dates were lowest. The bump of positive and important memories in young adulthood in Study 1 and in Berntsen and Rubin (2002) can thus be explained in terms of retrieval via life scripts, according to the results obtained in Study 2. The high number of no reports of memories of being most jealous, most angry, and most afraid might similarly reflect a lack of life script to support the retrieval of such events.

In addition to structuring retrieval by providing search descriptions, life scripts can also function as a mechanism of maintenance by repeatedly structuring retrieval over time and thus can form the basis for spaced practice of the types of events included in the script. The monotonically decreasing retention functions for most of the negative memories can simply reflect ordinary forgetting in the absence of life scripts to form search descriptions for and to maintain the accessibility of remote events of this type. According to this account, if no life script exists for highly positive and important events, similar monotonically decreasing curves would be found for such memories. Life scripts as a vehicle for maintenance via spaced practice can also explain why only important positive memories formed a bump in the 20s in Study 1, whereas important memories that were rated negative or mixed showed ordinary forgetting. The same is true of the differences between the life span distributions of positive and negative involuntary memories, reported by Berntsen and Rubin (2002). In short, retrieval and maintenance via a life script can explain most of the reduced recall of remote negative events discovered by Berntsen and Rubin (2002) and in Study 1.

Cognitive psychologists tend to focus on the level of the individual in providing explanations for their data and developing models of organization (Wallach \& Wallach, 1983). This has also been the case for theories of the bump. So far, the prevalent explanations of this phenomenon have concerned special encoding or consolidation processes in young adulthood that are due to either the formation of an adult identity or the increased number of landmark events in this time period (see Rubin et al., 1998, for a review). According to the present findings, however, the bump might primarily be a result of retrieval processes and spaced practice structured by culturally shared scripts on the temporal location of different types of life events. This explanation is more parsimonious than the previous ones. Any theory on the life course needs to include the conception of life script (e.g., Foner \& Kertzer, 1979; Neugarten \& Hagestad, 1976; Settersten \& Hagestad, 1996a, 1996b), as does an account of the findings of Berntsen and Rubin (2002) and Study 1. It is, on the other hand, not clear whether a defense mechanism or extraordinary encoding in the service of a self is needed. Thus, explanations centering on the individual might be superfluous.

As argued in the introduction, knowledge of the content and timing of transitional events is a powerful regulator of behavior in all societies. The present findings indicate that this knowledge also provides important structures for autobiographical memory. Societies are segmented into domains, such as work and family, each with its own transition points along the life course, so that a multiplicity of time tables exists (Neugarten \& Hagestad, 1976). Thus, life scripts can be seen to provide both a temporal and thematic organization for autobiographical memory, and thus enable individuals to think of their personal lives in terms of thematically distinct, but temporally overlapping life time periods (Conway \& Pleydell-Pearce, 2000). However, according to the present view, such themes derive primarily from the way shared cultural knowledge is organized and not from the way an individual-considered as an independent, unified self-chooses to compose his or her life narrative. Cultural knowledge provides powerful constraints for individual memory. Luborsky (1993) suggested that cultural age norms should be considered a default struc- 
ture in the organization of individual life stories. According to his findings, depressed individuals tell life stories that focus on deviations from the expected life course pattern and use such deviations as "idioms of distress" (p. 450), whereas nondepressed people tend to describe their life stories as consistent with the expected life course pattern. Thus, a life story reflecting a life script is a way of expressing satisfaction with life, whereas deviations are used to draw attention to problems, unhappiness, or things that did not work out. In both cases, knowledge of shared cultural norms is needed for one to understand the stories and their implications.

As argued earlier, the dissociation between positive and negative memories in relation to the bump is also consistent with a cognitive account modified by, for example, social censure, or with a narrative/identity account modified by defense mechanisms. However, the present explanation based on culturally shared life scripts has the advantage of being more parsimonious, making specific predictions about each tested emotion, and draws upon the well-defined psychological construct of script, as well as central concepts in fields outside of psychology.

\section{REFERENCES}

Baltes, P. B., \& Goulet, L. R. (1971). Exploration of developmental variables by manipulation and simulation of age differences in behavior. Human Development, 14, 149-170.

Belli, R. F., Schuman, H., \& Jackson, B. (1997). Autobiographical misremembering: John Dean is not alone. Applied Cognitive Psychology, 11, 187-209.

Berntsen, D., \& Rubin, D. C. (2002). Emotionally charged memories across the life span: The recall of happy, sad, traumatic, and involuntary memories. Psychology Aging, 17, 636-652.

Bluck, S., \& Habermas, T. (2000). The life story schema. Motivation \& Emotion, 24, 121-145.

Butler, R. N. (1964). The life review: An interpretation of reminiscence in the aged. In R. Kastenbaum (Ed.), New thoughts on old age (pp. 265-280). New York: Springer-Verlag.

Charles, S. T., Reynolds, C. A., \& Gatz, M. (2001). Age related differences and change in positive and negative affect over 23 years. Journal of Personality \& Social Psychology, 80, 136-151.

Clausen, J. A. (1995). Gender, contexts, and turning points in adults' lives. In P. Moen, G. Elder, \& K. Luschen (Eds.), Examining lives in context: Perspectives on the ecology of human development (pp. 365398). Washington, DC: American Psychological Association.

Cohen, G., \& FaulKner, D. (1988). Life span changes in autobiographical memory. In M. M. Gruenberg, P. E. Morris, \& R. N. Sykes (Eds.), Practical aspects of memory: Current research and issues. Vol. 1: Memory in everyday life (pp. 277-282). New York: Wiley.

Conway, M. A., \& Haque, S. (1999). Overshadowing the reminiscence bump: Memories of a struggle for independence. Journal of Adult Development, 6, 35-44.

Conway, M. A., \& Pleydell-Pearce, C. W. (2000). The construction of autobiographical memories in the self-memory system. Psychological Review, 107, 261-288.

de Vries, B., Blando, J., Southhard, P., \& Bubeck, C. (2001). The times of our lives. In G. Kenyon, P. Clark, \& B. de Vries (Eds.), Narrative gerontology: Theory, research and practice (pp. 137-158). New York: Springer-Verlag.

Ekman, P. (1992). Are there basic emotions? Psychological Review, 99, 550-553.

ErIKSON, E. (1950). Childhood and society. New York: Norton.

FitzGerald, J. M. (1988). Vivid memories and the reminiscence phenomenon: The role of a self narrative. Human Development, 31, 261273.
FitzGerald, J. M. (1996). Intersecting meanings of reminiscence in adult development and aging. In D. C. Rubin (Ed.), Remembering our past: Studies in autobiographicalmemory (pp. 360-383). Cambridge: Cambridge University Press.

Foner, A., \& KERTZER, D. I. (1979). Intrinsic and extrinsic sources of change in life-course transitions. In M. W. Riley (Ed.), Aging from birth to death: Interdisciplinaryperspectives (pp. 121-126). Boulder, CO: Westview Press.

Fromholt, P., \& LARSEn, S. F. (1991). Autobiographical memory in normal aging and primary degenerative dementia (dementia of the Alzheimer type). Journal of Gerontology: Psychological Sciences, 46, 85-91.

Fromholt, P., \& LARSEN, S. F. (1992). Autobiographical memory and life-history narratives in aging and dementia (Alzheimer type). In M. A. Conway, D. C. Rubin, H. Spinnler, \& W. Wagenaar (Eds.), Theoretical perspectives on autobiog raphical memory (pp. 413-426). Dordrecht: Kluwer.

Harber, K. D., \& Pennebaker, J. W. (1992). Overcoming traumatic memories. In S.- $\mathrm{A}$. Christianson(Ed.), The handbookof emotion and memory: Research and theory (pp. 359-387). Hillsdale, NJ: Erlbaum.

Holmes, A., \& Conway, M. A. (1999). Generation identity and the reminiscence bump: Memories for public and private events. Journal of Adult Development, 6, 21-34.

Hyland, D. T., \& ACKerman, A. M. (1988). Reminiscence and autobiographical memory in the study of the personal past. Journals of Gerontology: Psychological Sciences \& Social Sciences, 43, 3539.

JANOFf-Bulman, R. (1988). Assumptive worlds and the stress of traumatic events: Applications of the schema construct. Social Cognition, 7, 113-136.

JANSARI, A., \& PARKIN, A. J. (1996). Things that go bump in your life: Explaining the reminiscence bump in autobiographical memory. Psychology \& Aging, 11, 85-91.

Lewis, M., Sullivan, M. W., Stanger, C., \& Weiss, M. (1989). Self development and self-conscious emotions. Child Development, 60, 146-156.

LUBORSKY, M. R. (1993). The romance with personal meaning in gerontology: Cultural aspects of life themes. The Gerontologist, 33, 445-452.

Matlin, M., \& Stang, D. (1978). The Pollyanna principle: Selectivity in language, memory and thought. Cambridge, MA: Schenkman.

MroczeK, D. K. (2001). Age and emotion in adulthood. Current Directions in Psychological Science, 10, 87-90.

Neugarten, B. L., \& Hagestad, G. O. (1976). Age and the life course. In R. Binstock \& E. Shanas (Eds.), Handbook of aging and social sciences (pp. 35-55). New York: Van Nostrand Reinhold.

PANKSEPP, J. (1992). A critical role for "affective neuroscience" in resolving what is basic about basic emotions. Psychological Review, 99, 554-560.

Poulsen, H. (1991). Conations. Aarhus, Denmark: Aarhus University Press.

Rubin, D. C., \& Kontis, T. C. (1983). A schema for common cents. Memory \& Cognition, 11, 335-341.

Rubin, D. C., Rahhal, T. A., \& Poon, L. W. (1998). Things learned in early adulthood are remembered best. Memory \& Cognition, 26, 3-19.

Rubin, D. C., \& Schulkind, M. D. (1997a). The distribution of autobiographical memories across the lifespan. Memory \& Cognition, 25, 859-866.

Rubin, D. C., \& Schulkind, M. D. (1997b). The distribution of important and word-cued autobiographical memories in 20,35, and 70 year-old adults. Psychology \& Aging, 12, 524-535.

Rubin, D. C., Stolzfus, E. R., \& Wall, K. L. (1991). The abstraction of form in semantic categories. Memory \& Cognition, 19, 1-7.

Rubin, D. C., Wallace, W. T., \& Houston, B. C. (1993). The beginnings of expertise for ballads. Cognitive Science, 17, 435-462.

Rubin, D. C., Wetzler, S. E., \& Nebes, R. D. (1986). Autobiographical memory across the adult lifespan. In D. C. Rubin (Ed.), Autobiographicalmemory (pp. 202-221). Cambridge: Cambridge University Press.

Ruch, L. O., Chandler, S. M., \& Harder, R. A. (1980). Life change and rape impact. Journal of Health \& Social Behavior, 21, 248-260. 
Ruch, L. O., \& Holmes, T. H. (1971). Scaling of life change: Comparison of direct and indirect methods. Journal of Psychosomatic Research, 15, 221-227.

Rutter, M. (1989). Pathways from childhood to adult life. Journal of Child Psychology and Psychiatry, 30, 23-51.

Schank, R. C. (1982). Dynamic memory. New York: Cambridge University Press.

Schank, R. C. (1999). Dynamic memory revisited. New York: Cambridge University Press.

Schank, R. C., \& Abelson, R P.(1977). Scripts, plan, and knowledge. In P. N. Johnson-Laird \& P. C. Wason (Eds.), Thinking: Readings in cognitive science (pp. 421-435). Cambridge: Cambridge University Press.

Schrauf, R. W., \& Rubin, D. C. (1998). Bilingual autobiographical memory in older adult immigrants: A test of cognitive explanations of the reminiscence bump and the linguistic encoding of memories. Journal of Memory \& Language, 39, 437-457.

Schuman, H., \& RiEger, C. (1992). Collective memory and collective memories. In M. A. Conway, D. C. Rubin, H. Spinnler, \& W. A. Wagenaar (Eds.), Theoretical perspectives on autobiographical memory (pp. 323-336). Dordrecht: Kluwer.
Settersten, R. A., \& Hagestad, G. O. (1996a). What's the latest? Cultural age deadlines for family transitions. The Gerontologist, 36, 178188.

Settersten, R. A., \& Hagestad, G. O. (1996b). What's the latest? II. Cultural age deadlines for educational and work transitions. The Gerontologist, 36, 602-613.

SHAI, D. (2002). Working women/cloistered men: A family development approach to marriage arrangements among ultra-orthodox Jews. Journal of Comparative Family Studies, 33, 97-115.

SHum, M. S. (1998). The role of temporal landmarks in the autobiographical memory processes. Psychological Bulletin, 124, 423-442.

Smith, C. A., \& Ellsworth, P. C. (1985). Patterns of cognitive appraisal in emotion. Journal of Personality \& Social Psychology, 48, 813-838.

Walker, R. W., Rodney, J. V., \& Thompson, C. P. (1997). Autobiographical memory: Unpleasantness fades faster than pleasantness over time. Applied Cognitive Psychology, 11, 399-413.

Wallach, M. A., \& Wallach, L. (1983). Psychology's sanction for selfishness: The error of egoism in theory and therapy. San Francisco: Freeman.

\section{APPENDIX A}

\section{Questions for Study 1}

1. At some point in their lives, many people have experienced an event in which they were extremely afraid and which they recall with fear. If you have at least one memory in which you feel very afraid, how old are you in the memory when you feel most afraid?

2. At some point in their lives, many people have experienced an event in which they were extremely proud of something that they did themselves and which they recall with pride. If you have at least one memory in which you feel very proud, how old are you in the memory when you feel most proud?

3. At some point in their lives, many people have experienced an event in which they were extremely jealous and which they recall with jealousy. If you have at least one memory in which you feel very jealous, how old are you in the memory when you feel most jealous?

4. At some point in their lives, many people have experienced an event in which they felt extremely in love and which they recall with love. If you have at least one memory in which you feel much in love, how old are you in the memory when you feel most in love?

5. At some point in their lives, many people have experienced an event in which they were extremely angry and which they recall with anger. If you have at least one memory in which you feel very angry, how old are you in the memory when you feel most angry?

6. At some point in their lives, many people have had an extremely important experience which made big changes in their lives or outlooks and which they recall as an epoch-making event. If you have at least one memory of an epoch-making event, how old were you when your most epoch-making event took place?

6a. If an age is given in Question 6, was this epoch-making event positive, negative, or mixed? 


\section{Questions for Study 2}

1. At some point in his or her life, this 70-year-old person has experienced an extremely happy event that he or she recalls with much happiness and warmth. How old do you think he or she is in his or her happiest memory?

2. At some point in his or her life, this 70-year-old person has experienced an extremely sad event that he or she recalls with much sadness and sorrow. How old do you think he or she is in his or her saddest memory?

3. At some point in his or her life, this 70 -year-old person has had an extremely important experience that made big changes in his or her life or outlook and that he or she recalls as an epoch-making event. How old do you think he or she was when his or her most epoch-making event took place?

4. At some point in his or her life, this 70-year-old person has experienced a traumatic event in which he or she or someone else was seriously injured, his or her own life or the life of someone else was in serious danger, and he or she was feeling deeply shocked, helpless, very afraid, and did not know what to do. For example, traumas might include serious accidents, assaults, abuse, the sudden death of somebody, life-threatening diseases, military combat, torture, etc. How old do you think he or she is in his or her most traumatic memory?

5. At some point in his or her life, this 70-year-old person has experienced an event in which he or she was extremely angry and which he or she recalls with anger. How old do you think he or she is in the memory when he or she feels most angry?

6. At some point in his or her life, this 70-year-old person has experienced an event in which he or she felt extremely in love and which he or she recalls with love. How old do you think he or she is in the memory when he or she feels most in love?

7. At some point in his or her life, this 70-year-old person has experienced an event in which he or she was extremely jealous and which he or she recalls with jealousy. How old do you think he or she is in the memory when he or she feels most jealous?

8. At some point in his or her life, this 70-year-old person has experienced an event in which he or she was extremely proud of something that he or she did themselves and which he or she recalls with pride. How old do you think he or she is in the memory when he or she feels most proud?

9. At some point in his or her life, this 70-year-old person has experienced an event in which he or she was extremely afraid and which he or she recalls with fear. How old do you think he or she is in the memory in which he or she feels most afraid?

(Manuscript received April 23, 2002;

revision accepted for publication August 4, 2002.) 